\title{
Review of Women's Higher Education in Saudi Arabia
}

\author{
Yahya Al Alhareth*, Ibtisam Al Dighrir, Yasra Al Alhareth \\ General Administration of Education in Najran Region, Ministry of Education, Riyadh, Kingdom of Saudi Arabia \\ *Corresponding author: alhareth_y@yahoo.com
}

Received December 01, 2014; Revised December 25, 2014; Accepted January 05, 2015

\begin{abstract}
In spite of the barriers that stand in front of women's education, their higher education opportunities have increased with the improvement of female higher education provision but the opportunities are still not able to provide the level of education needed to meet the demand of women or to provide equality of access across the country. Thereby, this paper will review the literature on women's higher education in Saudi Arabia considering several different aspects including history, pedagogy, teaching methods and barriers.
\end{abstract}

Keywords: Saudi women, higher education, pedagogy, barriers

Cite This Article: Yahya Al Alhareth, Ibtisam Al Dighrir, and Yasra Al Alhareth, "Review of Women's Higher Education in Saudi Arabia.” American Journal of Educational Research, vol. 3, no. 1 (2015): 10-15. doi: 10.12691/education-3-1-3.

\section{Introduction}

The Ministry of Higher Education was established in 1975 to provide higher education to all students based on Islamic laws and to supervise its process [27]. The goal of education for women was for them to be successful housewives and good mothers, with knowledge suitable to their nature such as teaching, nursing or giving medical treatment. Gender segregation was essential at all levels except for kindergarten, day care and medical school [925], and this system continued until the opening of the King Abdullah University of Science and Technology in 2009, which is coeducational [20].

Women's Higher Education in Saudi Arabia was first established in 1962 in Riyadh through a special program called ENTSAB with education off-campus except for exams. From 1967, the King Abdulaziz University, in Jeddah, began to allow women to attend campus and the Girls Education College was started in Makkah. Since then, further institutions have been opened under the Ministry of Education [4-19]. Numbers have gradually risen as has investment in women's education [22-27], so there are now twenty-four public universities, most of which accept females, with the exception of the University of Petroleum and Minerals in Dhahran and the Islamic University in Al-Madinah [5-30], including the Princess Nora Bint Abdul Rahman University with 40,000 female students and more are planned (see Table 1) [9-30].

The Saudi government has invested heavily in its higher education programme and the Princess Nora Bint Abdul Rahman University offers courses in science that were previously restricted to male students, so the situation regarding women's higher education opportunities has continued to improve [27]. Women can now study abroad and the numbers have increased from roughly 3,879 in $2004 / 2005$ to approximately 35,700 in $2011 / 2012$, (see Figure 1) [29].

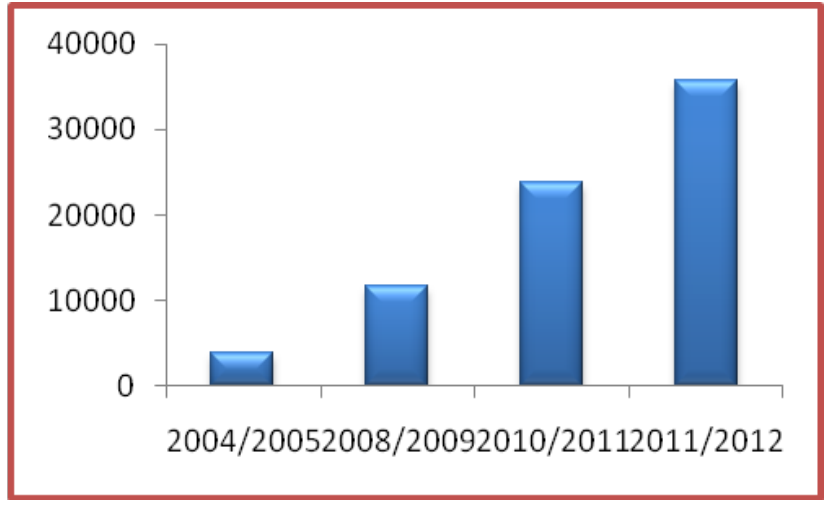

Figure 1. Saudi females studying abroad for a bachelor degree and above for the year 2004/2005, 2008/2009, 2010/2011 and 2011/2012 [29]

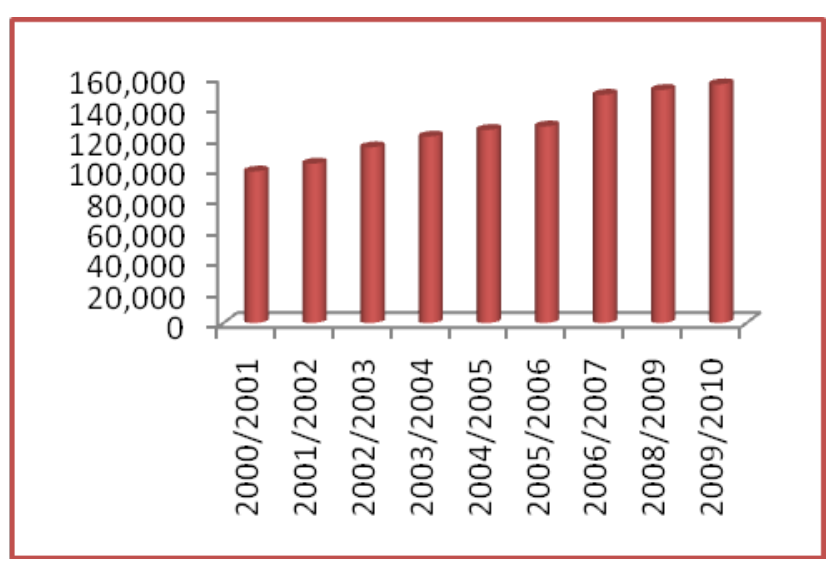

Figure 2. Female graduating secondary school from 2000/2001 to 2009/2010 in Saudi Arabia [29]

However despite all the efforts being made, women who live in the Northern and Southern regions still continue to have less opportunities to access higher education than those who live in the other regions because of the distribution of universities and their branches 
between regions and provinces, and the barriers of traditional culture [12-27]. Because of the increasing number of secondary school graduates year-on-year, there is also a rise in the demand for higher education places (see Figure 2) [5]. Supporting this view, in 2008 for example, only 73 percent of female secondary school graduates were offered higher education places by Saudi universities, but the Najran and Northern Border regions showed the lowest rate of offering university seats to female, compared to other regions, with only 1.4 percent offered a place at the universities in these regions. This means that their opportunities to access higher education are still less than other females in major regions (Riyadh, Jeddah and Dammam) [29]. However, despite these barriers, the demand for higher education by women has increased as more females graduate from secondary school, 99,000 in $2000 / 2001$ to 155,000 in $2009 / 2010$, (see Figure 2) [28,29].

The number of female lecturers in Saudi universities has correspondingly risen from just 4,700 in 2003/2004 to approximately 19,600 by $2008 / 2009$, whereas male instructors have increased from about 7,200 to around 48,800 in the same period [29]. However, since there are more female students than males there is still a lack of female instructors in higher education (see Figure 3).
This shortage of female instructors, along with the growth in number of females graduating from secondary school every year [4], causes excess demand. However, it is very difficult for women to attend university since they need a male guardian [7-40]. Therefore, opportunities for women to access higher education in Saudi Arabia are hampered [12].

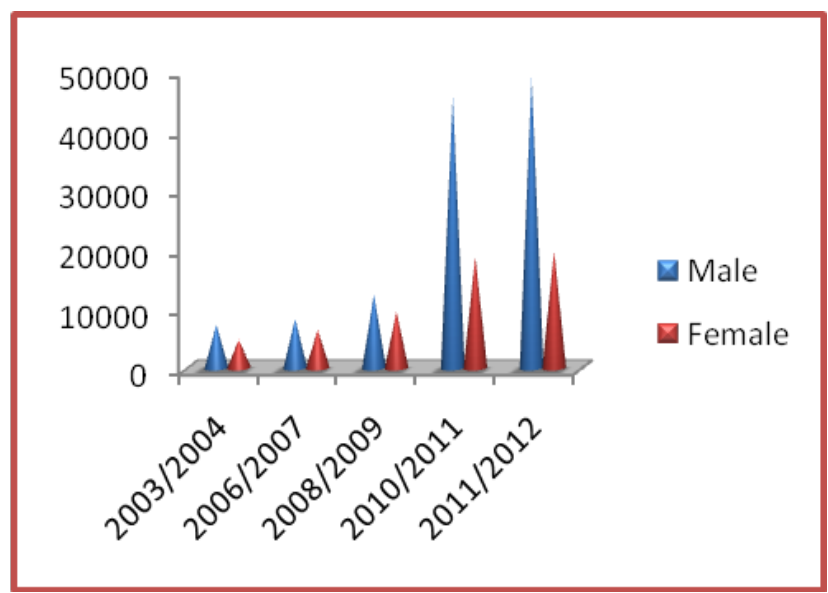

Figure 3. Saudi male and female academic staff at university for the years 2003/2004, 2006/2007, 2008/2009, 2010/2011 and 2011/2012 [29]

Table 1. Saudi universities [30]

\begin{tabular}{|c|c|c|c|c|c|c|}
\hline Region & University & Year & City & Type & \multicolumn{2}{|c|}{ Total } \\
\hline \multirow{13}{*}{ Riyadh } & King Saud & 1957 & Riyadh & Public & \multirow{13}{*}{13} & \\
\hline & Al-lmam Mohammad ibn Saud Islamic & 1974 & Riyadh & Public & & \\
\hline & Arab Open & 2002 & Riyadh & Private & & \\
\hline & Prince Sultan & 2000 & Riyadh & Private & & \\
\hline & Dar Al Uloom & 2005 & Riyadh & Public & & \\
\hline & Alfaisal & 2007 & Riyadh & Private & & \\
\hline & King Saud bin Abdulaziz University for Health Sciences & 2005 & Riyadh & Public & & \\
\hline & Al Yamamah & 2004 & Riyadh & Private & & \\
\hline & Princess Nora Bint AbdulRahman & 2007 & Riyadh & Public (women only) & & \\
\hline & Saudi Electronic & 2011 & Riyadh & Public & & \\
\hline & Shaqra University & 2010 & Shaqra & Public & & \\
\hline & Salman bin Abdulaziz & 2010 & Al Kharj & Public & & \\
\hline & Al Majma'ah & 2010 & Al Majma’ah & Public & & \\
\hline & King Abdulaziz & 1967 & Jeddah & Public & & \\
\hline & Effat University & 1999 & Jeddah & Private (women only) & & \\
\hline Makkah & Umm Al-Qura & 1949 & Makkah & Public & 5 & \\
\hline & King Abdullah University of Science and Technology & 2009 & Thuwal & Private & & \\
\hline & University of Dammam & 2010 & Dammam & Public & & \\
\hline Factorn & King Faisal & 1975 & Al Ahsa & Public & 4 & \\
\hline Eastern & King Fahd University for Petroleum and Minerals & 1963 & AlDahran & Public & 4 & \\
\hline & Prince Mohammad & 2006 & AlKhobar & Private & & \\
\hline Almoding & Islamic University & 1961 & Almadinah & Public & 2 & \\
\hline Almedina & Taibah University & 2003 & Al Madinah & Public & 2 & \\
\hline Asir & King Khalid & 1999 & Abha & Public & 1 & \\
\hline AlQassim & Qassim University & 2004 & Buraydah & Public & 1 & \\
\hline AlJouf & AlJouf University & 2005 & Al Jouf & Public & 1 & \\
\hline Jazan & Jazan University & 2006 & Jazan & Public & 1 & \\
\hline Ha’il & University of Hail & 2005 & Ha’il & Public & 1 & \\
\hline Al Baha & AlBaha University & 2006 & Al Baha & Public & 1 & \\
\hline Tabuk & Tabuk University & 2006 & Tabuk & Public & 1 & \\
\hline Najran & Najran University & 2006 & Najran & Public & 1 & \\
\hline Northern Border & Northern Border University & 2007 & Arar & Public & 1 & \\
\hline
\end{tabular}

Based on the above discussion, the goal of education for women needs to be changed as the requirements of today's women are completely different from those of their mothers and grandmothers because social changes are more likely to occur as women become more educated, more knowledgeable about their rights and more active than before. The women who have the chance to study abroad and are still studying are expected to come back with new ideas about the life that they want from their society and government as their number gradually increased (see Figure 1). Therefore, the government needs to do more than just increase its spending in women education by involving women in any decision that would impact their lives and ensure their ability to benefit from it such as through the use of the e-learning method. However, this depends on the goal the government seeks 
to achieve with women education; it implicitly appears good but is not in its entirety because of the noninvolvement of women in determining the appropriate education for them as decisions are usually made by men who usually look for things that do not affect their power.

\section{Pedagogy}

Traditional methods of teaching where students play no active role are common [27-38] and much memorising without creative thinking or discussion is the norm [10]. Students are expected to accept what they hear from their teachers or read from their textbooks and their role is to learn the information, which is reflected in the way their personality develops [12].

Some, such as reference [12] advocate the adoption of more modern methods, e.g. student-centred, active learning using brainstorming, teamwork and inventive thinking. The government launched the King Abdullah Bin Abdul Aziz Project for Developing Public Education (Tatweer) in 2007, with a budget of SAR 11.8 billion, to modernise the educational system and introduce modern technologies such as the internet and computer applications [2-38] starting at secondary level where students will adapt more easily [38], but also to develop teachers' skills and enhance and improve school activities [2-9].

Even at university level, students do not carry out research and are expected to rely on lectures for their learning [3]. However, innovation in teaching has begun and active learning strategies are now being used at some universities [5]. Women's education also uses passive methods [16] and it is suggested that lecturers merely reflect their own experience in their methods of delivery [11], though improvements have been noted in quality and variation of education received by women in Saudi Arabia [40]. Therefore, the Saudi government is working to develop the quality of its education system and considerable change is being seen.

\section{Teaching Methods}

The Ministry of higher Education seeks to develop methodologies for women's education based on Islamic law and social norms. ENTSAB was used at first and Ministry of Higher Education offered a distance education programme at Girls' Colleges from 2006 which used Very Small Aperture Terminal (VSAT), broadcasting technology to allow remote access to master's degrees $[7,8,9]$. Women can also watch lectures given by male instructors on closed-circuit television [4], hence avoiding the problem of attending class and reference [8] suggests that public universities should allow females to receive lectures from male staff using closed-circuit television with one-way video and a two-way audio broadcast system. Recently, ENTSAB has been improved to operate off-campus for the new Enhanced Distance Education where students can interact directly with their instructors via the internet [21]. This is a major development made possible by the advances in telecommunication infrastructure in recent years. This means that students are able to access satellite broadcasts and alongside using the internet [17], it makes education more accessible for women. The new ENTSAB says enrolment has risen from $4 \%$ in $2000 / 2001$ to $28 \%$ in $2003 / 2004$, however, as the number of places increased the take-up did not keep pace even though access to university became easier (see Figure 4) [29].

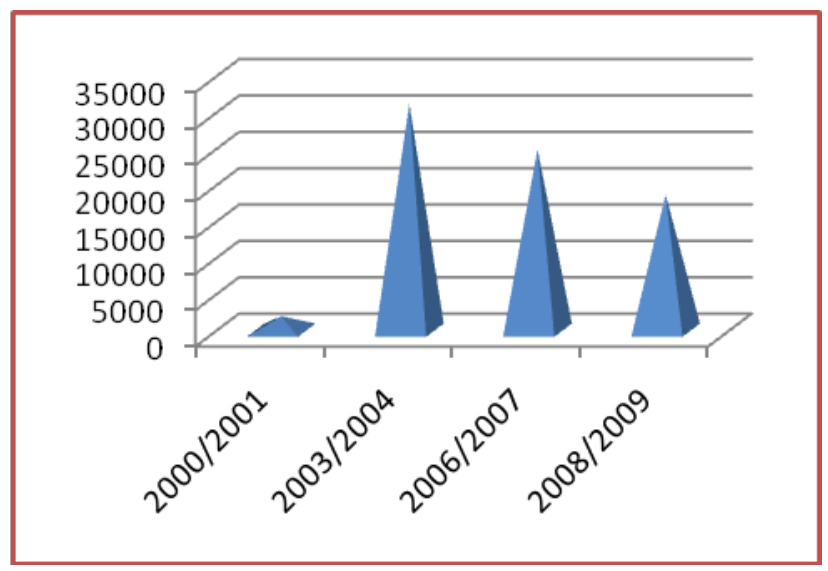

Figure 4. Saudi female enrolment for a bachelor degree at universities through the ENTSAB methods for the years 2000/2001, 2003/2004, 2006/2007 and 2008/2009 [29]

\section{Barriers}

Even though civilisation has brought many changes to the social and religious practices within Muslim communities, transition towards accepting education acquisition by Islamic women, especially higher education, has been faced with many obstacles, which infers rejection in many Islamic countries. Saudi Arabia is not an exception considering that the Saudi higher education system changed to improve education equity, with consequent gender parity, only in the last decade [34]. Religious beliefs coupled with social practices with regard to gender-based roles have resulted in the perception that higher education is more relevant to males than females, hence the institutionalisation of very few schools for women. Because of this, fewer education opportunities are presented to women.

Moreover, in the past, gender segregation has been employed to restrict Saudi women to particular study fields. In the recent past, the Saudi Government has emphasised the need for equity and acquisition of higher education by women in order to enhance their education status in society. In addition, in Islam, it is believed that education for both genders should be available $[11,12,13,14]$ and the 1970 Saudi education policy stated that women and men have an equal right to education [25]. However, barriers pose difficulties, for example, they have to call in advance for their required education materials from King Fahad Public Library in Riyadh and send a man to pick them up because they are not allowed to use the library in person [18], and must have a close male relative (mahram) as guardian to be eligible for a government scholarship to study abroad [28]. This indicates that improving laws related to women is required to support their educational capabilities.

Social and religious beliefs obstruct female education to a greater or lesser degree depending on their location in the country [12]. The social norms dictate how Saudi 
women behave, for example, Dorter's 1997 study [cited in 6] shows that an explanation given by a female research participant on a distance course demonstrates that the mere presence of men inhibits the learning possibility of women [6] as one woman cites how she felt obliged to leave a distance learning chat room when a male friend of her family entered. Reference [36] agree that there is a strong relationship between culture and learning, which is reflected in the way people prefer to learn and reference [39] noticed that communication between genders is affected by cultural, social and religious inputs. This shows the need to reduce the impact of social and religious beliefs towards the ability of women to learn.

A notable Saudi women's rights activist Wajeha AlHuwaidar, interviewed by Hurra TV in 2007, said that in general women in Saudi Arabia live in prison because they face five types of shackles, namely tribe, family, religious institutions, political organisation and society [26]. However, not all Saudi women agree to remove the rule of male guardianship over women such as Saudi women's rights activist Rowdah Al Yousef who has adopted the campaign "My Guardian Knows what's Best for $M e$ ", which aims to stand against those women who are demanding to be treated as adults by supporting the continuance of women guardianship [23]. Therefore, policy-makers must be aware of the effect of culture and religion on all aspects of life to be successful in implementing new policies and innovation [5]. In effect it is not enough to merely set up education for women, it must be set up to be accessible to women.

It is clear that segregation, mobility, early marriage, family honour and veiling are the main social and religious beliefs of Saudi society that impact on women's higher education [1]. Gender segregation is required in almost all situations, including virtual environments, and this will influence women's education [7-14]. A literal interpretation of the Qur'an shows that any type of communication between unmarried or unrelated males and females is restricted [14], and a man cannot talk directly to a woman not related to him, even via the internet [7-32], to avoid sexual attraction (fitna) according to reference [25]. Indeed, a case where a father killed his daughter for being on Facebook with a man has been recorded [24], though this is due to traditional values rather than religious beliefs [31]. Gender segregation, as a societal need to derail women in their professional life, has been employed to restrict Saudi women to particular study fields.

In addition, since men are responsible for their women (female family members), their permission is required for a woman to leave their home [7-15]. The practice of male guardian provision to women intending to pursue education abroad is mitigated to allow more women access to international education. Therefore, women's mobility is very restricted [35] by culture, which could affect their higher education opportunities. This implies that the subordination of women to men needs to be removed in order to enhance women's ability to live their own life. Moreover, according to reference [12], early marriage is one of the major factors that obstruct females' education. Women may drop out of school or higher education in order to marry, especially in rural areas where marriage is still a priority over education. This would unfavourably influence their chances of completing their higher education [ibid]. This shows that women could easily miss out on education opportunities by being forcefully married off.

Additionally, family honour in Saudi society is directly related to women's chastity [17-25]. Reference [[37], p. 18] explains that in society and in Islam "the woman is the repository of moral deeds in her family, thus she can destroy the honour of the family. She carries her family honour with her even after marriage and she continues to represent her family through modesty." Therefore, this can further restrict women's mobility and in turn might limit their higher education [14-40]. Furthermore, the requirement for women to cover their body with an abaya, their hair with a hijab and their face with a veil when they meet a person not related to them, as such might affect their chance of getting married, especially in remote areas [25-31], has led to the segregation of women.

These beliefs permeate society and cannot be ignored by the government when new policies are set because of the high degree of their influence on the social lives of women. Therefore, the adoption of e-learning could be an important step towards addressing these barriers in a number of ways. First, e-learning will enable teaching these women practical skills that put them on equal footing with male students. This will help provide such women with the required skills and knowledge in areas such as law, human rights and politics among others. Secondly, the barrier of mobility will be addressed by the adoption of e-learning since these students will have enhanced flexibility in accessing course and single gender lectures from all corners of the country. It is important to note that access to traditional classroom is limited for Saudi women since they are prohibited from driving. In addition, e-learning will ensure that those women who have been forced into early marriages get the opportunity to continue with their education from their homes. This is because e-learning ensures that such women interact with women faced with a similar challenge and thus provides a platform for initiating change in their situation. On the other hand, the adoption of e-learning might be an a step towards entrenching these barriers deeper, but the idea of finding new ways for women who are restricted by these beliefs of society is the main goal and it is better than to leave them without a chance of completing their studies.

In spite of the barriers that stand in front of women's education, the Saudi government, especially in the last decade, has obviously showed its commitment to move forward at all levels in general and in higher education, particularly by increasing the higher education institutions and distributing them in the whole country to ensure that all women can easily access them [27]. This direction was mainly driven by King Abdullah bin Abdulaziz and his vision towards Saudi women's role in society. For example, King Abdullah offers women a valuable opportunity to study abroad as is the case for men, which is definitely a huge movement for them to be educated in a society that gives men priority over women. Interestingly, King Abdullah has succeeded in this trend and made it run smoothly without any conflict within society [13-33]. This implies that the acceptance of the ability to move women's education further within society existed but needed to be supported by the government. 


\section{Conclusion}

It must be said that women's higher education opportunities have increased with the improvement of female higher education provision but the opportunities are still not able to provide the level of education needed to meet the demand of women or to provide equality of access across the country. The provision and opportunities are far better for those in the larger cities while for women in more remote parts of the country, access is almost impossible. Even for those in the urban areas near larger universities, access to higher education is limited by many factors including culture, society and religion. However, the Saudi government is on the right path in the improvement of its women's education and should continue doing so as education would probably enhance their status in society in may ways.

\section{References}

[1] Al Alhareth, Y., (2013), E-Learning Contribution to the Enhancement of Higher Education Opportunities for Women in Saudi Arabia (Pilot Study), US-China Education Review A\& B, USA, 3 (9): pp. 637-648.

[2] Al Shemary, A. (2007) the King Abdullah Project for the Development of Public Education. Asharq Alawsat Newspaper, $18^{\text {th }}$ April.

[3] Al Shubaily, S.A., (2008). Autonomous Learning in Teaching Translation: A Comparative Study between Conventional Teaching and Autonomous Learning, MA Dissertation, King Saud University.

[4] Alaugab, A., (2007), Benefits, barriers, and attitudes of Saudi female faculty and students toward online learning in higher education, PhD Thesis, Lawrence: University of Kansas

[5] Alebaikan, R., (2010), Perceptions of Blended Learning in Saudi Universities, PhD Thesis, University of Exeter

[6] Al-Harthi, A., (2005), Distance Higher Education Experiences of Arab, the International Review of Research in Open and Distance Learning Journal, 6 (3): pp. 1-14.

[7] Al-Kahtani, N.K.M., Ryan, J.J.C.H. \& Jefferson, T.I., (2006), How Saudi female faculty perceive internet technology usage and potential. Information Knowledge Systems Management, 5: pp. 227-243.

[8] Al-Khalifa, H. S., (2009), The State of Distance Education in Saudi Arabia, eLearn Magazine [online], available at: http://elearnmag.acm.org/archive.cfm?aid=1642193, [Accessed: 01/11 2014].

[9] Al-Khalifa, H. S., (2010c), elearning in Saudi Arabia. In: Demiray, U., et al., (2010). E-Learning Practices, Cases on Challenges Facing E-Learning and National Development: Institutional Studies and Practices, Volume II, Anadolu University, pp. 745772.

[10] Al-Mengash, S. A. (2006), an Analysis Study of the Saudi Education Policy and Recommendation for its Development. King Saud University Journal of Islamic Studies and Educational Science, 19(1), 381-440.

[11] AlMunajjed, M., (1997), Women in Saudi Arabia Today, London: Macmillan.

[12] AlMunajjed, M., (2009), Women's Education in Saudi Arabia: The Way Forward, New York: Booz \& Company Inc.

[13] Alzouman, A., (2014), highlighted the achievements of Saudi women in the era of King Abdullah bin Abdulaziz [online], althamena program report, mbc.net, available at: http://www.mbc.net/ar/programs/althamena/articles/, [Accessed: $12 / 11 / 2014)$.

[14] Baki, R., (2004). Gender-segregated education in Saudi Arabia: Its impact on social norms and the Saudi labor market. Education Policy Analysis Archives, 12 (28): p. 1-12.

[15] Deaver, S., (1980), The contemporary Saudi women. In: Bourguignon E, ed. A world of women: anthropological studies of women in the societies of the World. New York: Praeger.
[16] Doumato, E., (2000), Getting God's Ear: Women, Islam, and Healing in Saudi Arabia and the Gulf. New York: Columbia University Press.

[17] Hamdan, A., (2005), Women and education in Saudi Arabia: Challenges and achievements. International Education Journal, 6 (1), 42-64.

[18] Human Rights Watch, (2008), Report on Human Rights Abuses Stemming from Male Guardianship and Sex Segregation in Saudi Arabia April 19, 2008, Human Rights Watch the United State of America.

[19] King Abdulaziz University, (2012), Deanship of distance education Overview [Online], Saudi Arabia, Available at: http://elearning.kau.edu.sa/Default.aspx?Site_ID=214\&Lng=EN [Accessed: 21/10/2014]

[20] King Abdullah University of Science and Technology, (2012), Overview [Online], Saudi Arabia, available at: http://www.kaust.edu.sa [Accessed: 10/11/2014]

[21] King Faisal University, (2012), e-learning and distance education Overview [Online], Saudi Arabia, Available at: http://www.kfu.edu.sa/en/Deans/elearning/Pages/intro.aspx [Accessed 21 April 2012].

[22] Krieger, Z. (2007), Saudi Arabia Puts Its Billions Behind Western Style Higher Education, The Chronicle of Higher Education, $14^{\text {th }}$ September.

[23] Leslie, L. (2011) Saudi Feminism doesn't Mirror Western Ideas. Muslim Voice, [Online] Available at: $<$ http://muslimvoices.org/saudi-feminism-mirror-western-ideas/> [Accessed: 23/10/2014].

[24] McElroy, D., (2008), Saudi women killed for chatting on Facebook. The Telegraph, $31^{\text {st }}$ March.

[25] Metz, H. C., (1992), Saudi Arabia: A Country Study, Washington: GPO for the Library of Congress, [Online] Available at: $<$ http://countrystudies.us/saudi-arabia/> [Accessed: 26/11/2014].

[26] Middle East Media Research Institute, (2007), For Saudi Women, Every Day Is a Battle, An interview with Wajeha Al-Huwaidar [Online], a Saudi women's rights activist, which aired on Hurra TV on May 26, 2007, UJA. Available at: http://www.memri.org/report/en/0/0/0/0/0/220/2224.htm, [Accessed: 26/10/2014].

[27] Ministry of Higher Education, (2009), the National Report June 2009, Saudi Arabia, Office of the Deputy Minister for Educational Affairs

[28] Ministry of Higher Education, (2010), Study in KSA [online], Saudi Arabia, Available at http://www.mohe.gov.sa/en/studyinside/Pages/default.aspx [Accessed: 02/11/2014]

[29] Ministry of Higher Education, (2013a) Higher Education Statistics Centre [online], Saudi Arabia, Available at http://www.mohe.gov.sa/ar/Ministry/Deputy-Ministry-forPlanning-and-Informationaffairs/HESC/Ehsaat/Pages/default.aspx [Accessed: 10/10/2014].

[30] Ministry of Higher Education, (2013b) Government and Privet Universities [online], Saudi Arabia, Available at http://www.mohe.gov.sa/ar/studyinside/GovernmentUniversities/Pages/default.aspx, [Accessed: 13/10/2014]

[31] Mirza, A., (2008), Students' Perceived Barriers to In-Class Participation in a Distributed and Gender Segregated Educational Environment, Electronic Journal of Information Systems in Developing Countries, 35 (8): pp. 1-17.

[32] Mohamed, A.H., Abuzaid, R.A, Banladen, R.M., (2008). Opportunities and Challenges Of The Knowledge Management Approach to E-Learning: A Case Study In Al-Bayan Model School For Girls, Kingdom Of Saudi Arabia, The Electronic Journal on Information Systems in Developing Countries, 35 (4): pp. 1-11.

[33] Nouf, M., (2014), women in King thought [online], authors and articles, Okaz Journal, available at: http://www.okaz.com.sa/new/issues/20140502/Con201405026966 23.htm, [Accessed: 20/1112014).

[34] Roy, D., (1992), Saudi Arabian education: development policy. Middle Eastern Studies, 28: pp. 477-508.

[35] Sabbagh, S., (1996), Arab Women: Between Defiance and Restraint. New York: Olive Branch Press.

[36] Samovar, A., Porter, E. and McDaniel, R., (2009), Communication Between Cultures, Boston: Wadsworth.

[37] Soffan, L. (1980). The Women of the United Arab Emirates, New York, NY: Harper \& Row, P. 18. 
[38] Tatweer, J. (2008) King Abdullah Project for General Education Development. Saudi Arabia Projects, [Online] Available at: $<$ http://www.tatweer.edu.sa/Pages/home.aspx > [Accessed 26 June 2012].
[39] Tubaishat, A., Bhatti, A., \& El-Qawasemah, E. (2006), ICT Experiences in Two Different Middle Eastern Universities. Issues in Informing Science and Information Technology, 3: pp. 667-678.

[40] World Bank, (2009), The Status and Progress of Women in the Middle East and North Africa, Washington: World Bank. 